\title{
Prevotella bergensis sp. nov., isolated from human infections
}

Correspondence

William G. Wade

william.wade@kcl.ac.uk

\author{
Julia Downes, ${ }^{1}$ lain C. Sutcliffe, ${ }^{2}$ Tor Hofstad $^{3}$ and William G. Wade ${ }^{1}$ \\ ${ }^{1}$ King's College London Dental Institute at Guy's, King's College and St Thomas' Hospitals, \\ Infection Research Group, London SE1 9RT, UK \\ ${ }^{2}$ Division of Biomedical Sciences, School of Applied Sciences, Northumbria University, \\ Newcastle upon Tyne NE1 8ST, UK \\ ${ }^{3}$ The Gade Institute and Haukeland University Hospital, Section of Microbiology and \\ Immunology, University of Bergen, Bergen N-5021, Norway
}

\begin{abstract}
Eight strains of anaerobic Gram-negative bacilli isolated from infections of the skin and soft tissues were subjected to a comprehensive range of phenotypic and genotypic tests. 16S rRNA gene sequence analysis revealed the strains to constitute a homogeneous group, distinct from species with validly published names but related to a cluster including Prevotella buccae, Prevotella dentalis and Prevotella baroniae. A novel species, Prevotella bergensis sp. nov., is proposed to accommodate these strains. Prevotella bergensis is saccharolytic and produces acetic and succinic acids as end products of fermentation. The $G+C$ content of the DNA of the type strain is $48 \mathrm{~mol} \%$. The type strain of Prevotella bergensis is $94067913^{\top}\left(=\mathrm{DSM} 17361^{\top}=\mathrm{CCUG}\right.$ $\left.51224^{\top}\right)$.
\end{abstract}

Members of the genus Prevotella (Shah \& Collins, 1990) are Gram-negative, moderately saccharolytic, bile-sensitive organisms that are part of the normal flora of the human mouth and vagina, and the rumen in various mammalian species (Shah et al., 1998). They are also frequently isolated from infections of the mouth and other body sites. In this study, eight strains of anaerobic Gram-negative bacilli isolated from skin and soft-tissue infections in humans were subjected to a range of phenotypic and genotypic tests.

Strains 94044900 and 94067937 were isolated from skin abscesses, strains $94067913^{\mathrm{T}}, 94068344,95002865$ and 95058389 were isolated from soft-tissue abscesses, 94082166 from a wound infection and 95062687 from a decubitus ulcer. Prevotella buccae CCUG $15401^{\mathrm{T}}$ was obtained from the CCUG, Prevotella dentalis DSM $3688^{\mathrm{T}}$ from the DSMZ and Prevotella baroniae E9.33 ${ }^{\mathrm{T}}$ from our collection (King's College London).

Strains were grown at $37^{\circ} \mathrm{C}$ on Fastidious Anaerobe Agar (FAA; LabM) supplemented with $5 \%$ horse blood under

Published online ahead of print on 2 December 2005 as DOI 10.1099/ ijs.0.63888-0.

Abbreviation: FAME, fatty acid methyl ester.

The GenBank/EMBL/DDBJ accession number for the $16 \mathrm{~S}$ rRNA gene sequence of $P$. bergensis DSM $17361^{\top}$ is AY350613.

Electron micrographs of $P$. bergensis, an extended phylogenetic tree and FAME analyses compared with other Prevotella species are available as supplementary material in IJSEM Online. anaerobic conditions $\left(80 \% \mathrm{~N}_{2}, 10 \% \mathrm{H}_{2}, 10 \% \mathrm{CO}_{2}\right)$ in an anaerobic workstation (Don Whitley Scientific). Colonial morphologies on this medium after 4 days incubation were viewed using a dissecting microscope. Cellular morphology was recorded after Gram-staining of smears prepared from 2-day FAA cultures. Hanging-drop preparations of $18-\mathrm{h}$ cultures of peptone/yeast extract/glucose (PYG) broth were examined under phase-contrast microscopy for cellular motility. Transmission electron microscopy was used to examine the cell-wall ultrastructure of strains $94067913^{\mathrm{T}}$ and 94068344 as described previously (Downes et al., 2000).

Fermentation tests were performed using pre-reduced, anaerobically sterilized (PRAS) sugars prepared in-house in an anaerobic workstation (Holdeman et al., 1977). Other biochemical tests were performed as described by Holdeman et al. (1977) and Jousimies-Somer et al. (2002). Bacterial strains were grown in peptone/yeast extract (PY) broth, with and without glucose and short-chain volatile and nonvolatile fatty acids, extracted by standard methods and analysed by gas chromatography (Holdeman et al., 1977), using a CP9002 instrument (Chrompak). Enzyme profiles were generated with the Rapid ID 32A anaerobe identification kit (bioMérieux), according to the manufacturer's instructions, using bacteria harvested from blood agar plates (Blood Agar Base no. 2; LabM) supplemented with 5\% horse blood, and performed in triplicate.

Cellular fatty acid composition was determined for all strains as described previously (Sutcliffe, 2000; Downes et al., 
2005). Fatty acid methyl esters (FAMEs) were identified by comparison with authentic FAME standards (Sigma). The $\mathrm{G}+\mathrm{C}$ content of the DNA of strains $94067913^{\mathrm{T}}$ and 94068344 was estimated by an HPLC method as described previously (Wade et al., 1999). A thermal denaturation method (Huß et al., 1983) was used to determine the extent of DNA-DNA hybridization between strains.

DNA extraction, PCR and sequencing of 16S rRNA genes were performed as described previously (Downes et al., 2005). Sequences were connected using the BioEdit program (Hall, 2004) and identified by BLAST interrogation of the GenBank database (Altschul et al., 1990). Related sequences were aligned using BioEdit and further phylogenetic analysis was performed using the PHYLIP suite of programs (Felsenstein, 1993). Specifically, a distance matrix was constructed using the Jukes-Cantor algorithm by means of DNADIST, and NEIGHBOR was used to construct phylogenetic trees which were viewed using TreeView (Page, 1996).

The eight strains were obligately anaerobic, non-motile, Gram-negative bacilli which were $0 \cdot 7-0 \cdot 8 \mu \mathrm{m}$ wide by $0 \cdot 8-6 \mu \mathrm{m}$ long. After 4 days incubation on FAA plates, colonies were $0 \cdot 6-0.8 \mathrm{~mm}$ in diameter, circular, entire, convex, opaque and grey to off-white in colour. Transmission electron microscopic examination of ultrathin sections through the cells of strains $94067913^{\mathrm{T}}$ and 94068344 showed the presence of a typical Gram-negative cell wall composed of a thin peptidoglycan layer surrounded by an outer membrane. In addition, a capsule was clearly visible around the cells of both strains (micrographs included as Supplementary Fig. S1 in IJSEM Online).

Growth of all strains in PY broth produced a moderately turbid suspension ( 2 to $3+$ on a scale of 0 to $4+$ ). Growth was enhanced ( 3 to $4+$ ) by the addition of $1 \%$ fermentable carbohydrates. Strains were saccharolytic and major amounts of acetic and succinic acids and a trace of isovaleric acid were produced as end products of metabolism in PYG. All strains hydrolysed aesculin but arginine, gelatin and urea were not hydrolysed. Indole and catalase were not produced and nitrate was not reduced. There was no growth in $20 \%$ bile. All strains were positive for $\beta$-galactosidase, $\alpha$-glucosidase, $\alpha$-arabinosidase, alkaline phosphatase, leucyl glycine arylamidase and alanine arylamidase in the Rapid ID 32A identification panel; reactions for $\beta$-glucosidase, $\beta$-glucuronidase, $\beta$ - $N$-acetyl-glucosaminidase, mannose fermentation, arginine arylamidase and glutamyl glutamic acid arylamidase were weak and variable. The $\mathrm{G}+\mathrm{C}$ content of the DNA of strains $94067913^{\mathrm{T}}$ and 94068344 was $48 \mathrm{~mol} \%$.

Phylogenetic analysis of the 16S rRNA gene sequence of strain $94067913^{\mathrm{T}}$ revealed this organism to be most closely related to species belonging to the genus Prevotella (Fig. 1). A fuller phylogenetic tree is available as Supplementary Fig. S2 in IJSEM Online. The most closely related species were Prevotella dentalis ( $90 \cdot 2 \%$ sequence identity), P. baroniae $(89 \cdot 1 \%)$ and P. buccae $(86 \cdot 7 \%)$. The $5^{\prime}$-end of the $16 \mathrm{~S}$ rRNA gene was sequenced for the remaining seven strains

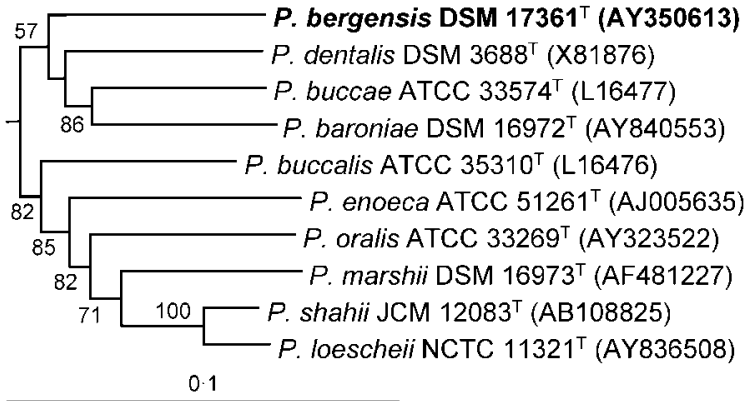

Fig. 1. Phylogenetic tree based on $16 \mathrm{~S}$ rRNA gene sequence comparisons over 1412 aligned bases showing the relationship between Prevotella bergensis sp. nov. and related species. The tree was constructed using the neighbour-joining method following distance analysis of aligned sequences. Numbers represent bootstrap values for each branch based on data for 100 trees. Accession numbers for 16S rRNA gene sequences are given in parentheses for each strain. Bar, 0.1 nucleotide substitutions per site.

and showed $\geqslant 98 \cdot 8 \%$ sequence identity to strain $94067913^{\mathrm{T}}$ over 485 unambiguously aligned bases.

DNA-DNA hybridization between strains $94067913^{\mathrm{T}}$ and 94068344 was determined to be $85 \%$. Relatedness between strain $94067913^{\mathrm{T}}$ and P. buccae CCUG $15401^{\mathrm{T}}, P$. dentalis DSM $3688^{\mathrm{T}}$ and $P$. baroniae $\mathrm{E} 9.33^{\mathrm{T}}$ was estimated at 16,15 and $4 \%$, respectively.

Cellular FAME results for the strains are available in Supplementary Table S1 in IJSEM Online. The non-hydroxy FAME profiles were consistent with those previously described for the genus Prevotella (Downes et al., 2005; Moore et al., 1994; Sakamoto et al., 2004), with methyl-branched fatty acids predominating (notably anteiso-C15:0). As noted previously (Downes et al., 2005), the use of acid-catalysed methanolysis in the FAME preparation may have prevented the recovery of hydroxy fatty acids. Rather than revise the description of the FAME composition of the genus Prevotella, we reemphasize our previous conclusion (Downes et al., 2005) that a comprehensive, standardized survey of FAME composition in the genus Prevotella is now warranted. Most significantly, in the present context, the FAME profiles for the strains described herein were similar to those previously reported for $P$. baroniae, consistent with the close relationship of these species deduced from the phylogenetic analysis, although iso-C14:0 was noted to be increased at the expense of iso- and anteiso-C17:0 FAMEs (see Supplementary Table S1).

The strains studied here constitute a homogeneous group and are clearly distinct from any species with validly published names. Although the level of 16S rRNA gene sequence identity with related strains is relatively low, this is true for the majority of species of Prevotella, which form a loose phylogenetic cluster. There are no phenotypic characteristics 
Table 1. Phenotypic characteristics that differentiate Prevotella bergensis sp. nov. from other Prevotella species

Species: 1, P. buccae; 2, P. dentalis; 3, P. oris; 4, P. salivae; 5, P. bergensis; 6, P. oralis; 7, P. baroniae; 8, P. buccalis; 9, P. loescheii; 10, P. veroralis; 11, P. multiformis; 12 , P. denticola; 13 , P. melaninogenica; 14, P. shahii; 15 , P. oulorum; 16, P. enoeca; 17, P. bivia; 18, P. tannerae; 19, P. intermedia; 20, P. nigrescens; 21, P. corporis; 22, P. marshii; 23, P. pallens; 24, P. disiens. W, Weak; V, variable.

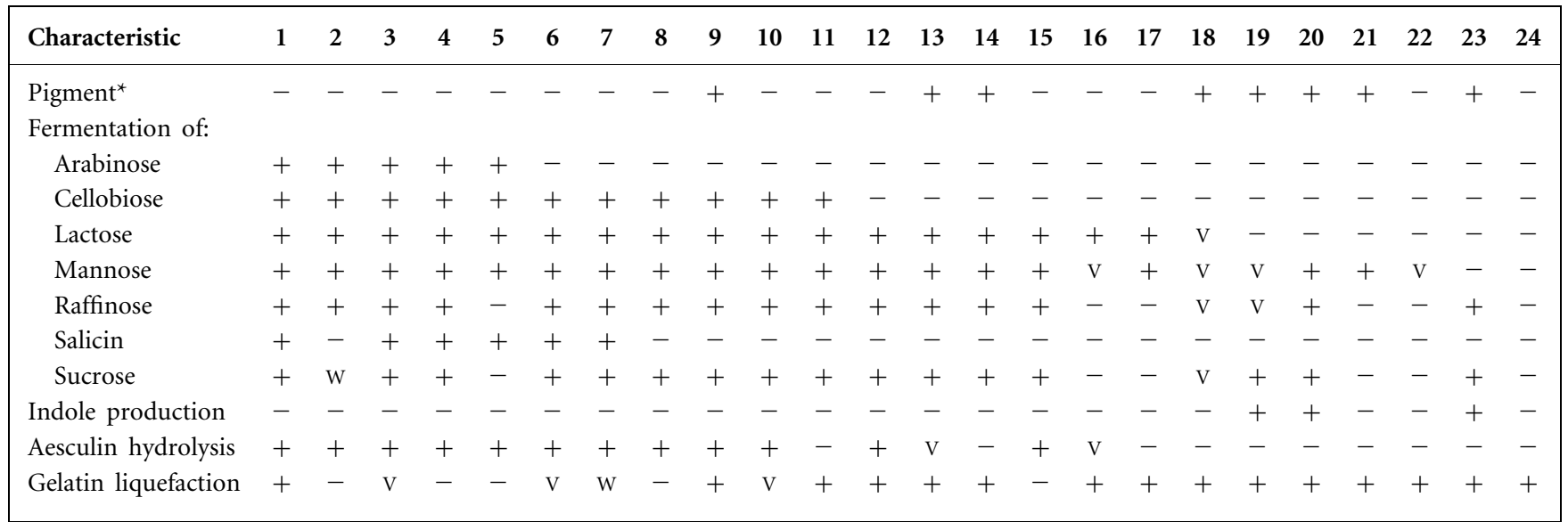

*Pigmentation on blood agar may take up to 14 days and varies from tan to brown to black depending on the species.

among Prevotella species which would support the subdivision of the genus. We therefore propose the name Prevotella bergensis sp. nov. for this group of strains. Phenotypic characteristics that differentiate $P$. bergensis from other Prevotella species are shown in Table 1.

\section{Description of Prevotella bergensis sp. nov.}

Prevotella bergensis (berg.en'sis. N.L. fem. adj. bergensis referring to Bergen, the Norwegian city where the first strains were isolated).

The description is based on eight strains isolated from human skin and soft-tissue abscesses. Biochemical results were identical for all strains studied. Cells are obligately anaerobic, non-motile, Gram-negative bacilli $(0 \cdot 7-0 \cdot 8 \mu \mathrm{m} \times$ $0 \cdot 8-6 \mu \mathrm{m})$. After 4 days incubation on FAA plates, colonies are $0 \cdot 6-0.8 \mathrm{~mm}$ in diameter, circular, entire, convex, opaque and grey to off-white in colour. Growth in broth media produces a moderate turbidity which is enhanced by the addition of fermentable carbohydrates. Cells are saccharolytic and ferment arabinose, cellobiose, fructose, glucose, lactose, maltose, mannose, rhamnose, salicin and xylose; mannitol and trehalose are fermented variably; melezitose, melibiose, raffinose, ribose, sorbitol and sucrose are not fermented. Major amounts of acetic and succinic acids and a trace of isovaleric acid are produced as end products of metabolism in PYG broth. The non-hydroxylated fatty acid profile is predominately iso-C14:0, iso-C15:0 and anteiso$\mathrm{C} 15$ : 0. Aesculin is hydrolysed; arginine, gelatin and urea are not hydrolysed. Indole and catalase are not produced and nitrate is not reduced. There is no growth in $20 \%$ bile. The $\mathrm{G}+\mathrm{C}$ content of the DNA of the type strain is $48 \mathrm{~mol} \%$.
The type strain is $94067913^{\mathrm{T}}\left(=\mathrm{DSM} 17361^{\mathrm{T}}=\mathrm{CCUG}\right.$ $\left.51224^{\mathrm{T}}\right)$. The type and other strains reported here were isolated from infections of the skin and soft-tissue abscesses.

\section{References}

Altschul, S. F., Gish, W., Miller, W., Myers, E. W. \& Lipman, D. J. (1990). Basic local alignment search tool. J Mol Biol 215, 403-410.

Downes, J., Olsvik, B., Hiom, S. J., Spratt, D. A., Cheeseman, S. L., Olsen, I., Weightman, A. J. \& Wade, W. G. (2000). Bulleidia extructa gen. nov., sp. nov., isolated from the oral cavity. Int J Syst Evol Microbiol 50, 979-983.

Downes, J., Sutcliffe, I. C., Tanner, A. C. R. \& Wade, W. G. (2005). Prevotella marshii sp. nov. and Prevotella baroniae sp. nov. isolated from the human oral cavity. Int J Syst Evol Microbiol 55, 1551-1555.

Felsenstein, J. (1993). PHYLIP - Phylogeny Inference Package, version 3.5c. Distributed by the author. University of Washington, Seattle, USA. Hall, T. (2004). BioEdit. Biological sequence alignment editor for Win95/ 98/NT/2000/XP. http://www.mbio.ncsu.edu/BioEdit/bioedit.html

Holdeman, L. V. H., Cato, E. P. \& Moore, W. E. C. (1977). Anaerobe Laboratory Manual, 4th edn. Blacksburg, VA: Virginia Polytechnic Institute and State University.

Huß, V. A. R., Festl, H. \& Schleifer, K. H. (1983). Studies on the spectrophotometric determination of DNA hybridization from renaturation rates. Syst Appl Microbiol 4, 184-192.

Jousimies-Somer, H., Summanen, P., Citron, D. M., Baron, E. J., Wexler, H. M. \& Finegold, S. M. (2002). Wadsworth Anaerobic Bacteriology Manual, 6th edn. Belmont, CA: Star Publishing.

Moore, L. V., Bourne, D. M. \& Moore, W. E. (1994). Comparative distribution and taxonomic value of cellular fatty acids in thirtythree genera of anaerobic gram-negative bacilli. Int J Syst Bacteriol 44, 338-347.

Page, R. D. M. (1996). TreeView: an application to display phylogenetic trees on personal computers. Comput Appl Biosci 12, 357-358. 
Sakamoto, M., Suzuki, M., Huang, Y., Umeda, M., Ishikawa, I. \& Benno, Y. (2004). Prevotella shahii sp. nov. and Prevotella salivae sp. nov., isolated from the human oral cavity. Int $J$ Syst Evol Microbiol 54, 877-883.

Shah, H. N. \& Collins, D. M. (1990). Prevotella, a new genus to include Bacteroides melaninogenicus and related species formerly classified in the genus Bacteroides. Int J Syst Bacteriol 40, 205-208.

Shah, H. N., Gharbia, S. E. \& Duerden, B. I. (1998). Bacteroides, Prevotella and Porphyromonas. In Topley \& Wilson's Microbiology and Microbial Infections, pp. 1305-1330. Edited by L. Collier, A. Balows \& M. Sussman. London: Arnold.
Sutcliffe, I. C. (2000). Characterisation of a lipomannan lipoglycan from the mycolic acid containing actinomycete Dietzia maris. Antonie van Leeuwenhoek 78, 195-201.

Wade, W. G., Downes, J., Dymock, D., Hiom, S. J., Weightman, A. J., Dewhirst, F. E., Paster, B. J., Tzellas, N. \& Coleman, B. (1999). The family Coriobacteriaceae: reclassification of Eubacterium exiguum (Poco et al. 1996) and Peptostreptococcus heliotrinreducens (Lanigan 1976) as Slackia exigua gen. nov., comb. nov. and Slackia heliotrinireducens gen. nov., comb. nov., and Eubacterium lentum (Prevot 1938) as Eggerthella lenta gen. nov., comb. nov. Int J Syst Bacteriol 49, 595-600. 